\begin{tabular}{|c|c|c|}
\hline & Int.J.Curr.Microbiol.App.Sci (2021) 10(12): 80-90 & \\
\hline & $\begin{array}{l}\text { International Journal of Current Microbiology and Applied Sciences } \\
\text { ISSN: 2319-7706 Volume } \mathbf{1 0} \text { Number } 12 \text { (2021) } \\
\text { Journal homepage: http://www.ijcmas.com }\end{array}$ & $\rightarrow 00$ \\
\hline $\begin{array}{l}\text { EXCELLENT } \\
\text { PUBLISHERS }\end{array}$ & & wwwi.jicmas com \\
\hline
\end{tabular}

Original Research Article

https://doi.org/10.20546/ijcmas.2021.1012.010

\title{
Formulation and Characterization of Gluten Free Bread based on Quinoa and Rice Flour
}

\author{
Mandaloju Pooja, Mishra Neha* and Prasad Ranu \\ Department of Food Nutrition and Public Health, Sam Higginbottom University of \\ Agriculture, Technology and Sciences, Prayagraj-211007, India \\ *Corresponding author
}

A B S T R A C T

Keywords

Gluten free bread, quinoa flour, rice flour, celiac diseases, gluten free diet, yeast

\section{Article Info}

Received: 04 November 2021 Accepted:

26 November 2021 Available Online: 10 December 2021
The aim of the present study is to formulate gluten free bread enriched with quinoa and rice flour. Physicochemical properties of flour including water absorption capacity, bulk density, foaming capacity, swelling capacity and emulsion capacity were analysed. Then sensory score of the product such as colour, flavour, taste, and overall acceptability and nutritional compositions includes moisture, ash, protein, fat, carbohydrate, energy were analyzed by Hedonic scale and AOAC method. Data was analysed by Analysis of variance (Two-way ANOVA or Two-way classification) technique treatment of the developed food products. The result of sensory score reported that treatment $\left(T_{2}\right)$ found to be best. The result of the present study revealed that rice flour and quinoa flour, enhance the nutritive value of gluten free bread.

\section{Introduction}

In last few years, the demand of gluten free diet has raised as the number of celiac patients is increasing. Celiac disease is auto-immune diseases that caused due to gluten insensitivity, can damage the stomach and small intestine (Crockett, 2009; et al.,). Celiac patients triggered to even only a small amount of gluten, a wheat protein that can lead to the small-intestine inflammation and thereby malabsorption of nutrients. Restriction of gluten diet for whole life is the only best treatment for celiac disease. Grains such as wheat, barley, rye are gluten rich and staple diet in most of the counties. Consuming alternative cereal grains and psedocereals such as sorghum, rice, teff, amaranth, buckwheat quinoa is one of the possible solutions to reverse the small intestine damage. In addition, theses grains have high nutritional quality and therapeutic properties. Gluten is the main structural protein in wheat which is required for desired volume and crumb 
structurein dough system. Gluten is made up of glutenin and prolamin, which provides elasticity and extensibility respectively. They are the primary ingredient in cereal-based products especially bakery products and provides a continuous gluten network, resulting in a proper crumb structure. Glutenfree products, especially yeast leaved bakery products, have few technological problems such as poor appearance, texture, sensory properties and reduced shelf life. Lack of gluten, results in weak batters, decreased volume and crumbly structure, therefore its removal is the serious problems for bakers. Non yeast leavened bakery products such as cakes, muffins, biscuits are easier to obtain because the lack of visco-elasticity of their batters is not an issue, as gas is generated during baking and immediately retained. Bakery products are convenient, ready to eat and liked by all age group. Lack of gluten matrix is the major issue in formation of gluten free leavened bread.

The gluten-free market is becoming the most prosperous market in the field of food and beverage in the near future (Agriculture and Agri-Food Canada, 2011). Commercial gluten free breads are pale, have poor flavour, taste and lack fibre, vitamins and nutrients. There is urgent need to investigate new ingredients and technologies that improve the textural, sensory and nutritional quality of gluten free bread. Different cereals and pseudo cereal such as rice, amaranths, quinoa have been utilized for developing gluten-free food products including breads, pasta, cookies. Of these, rice flour as been used as basic ingredient in gluten-free bread, due to its lack of gluten, and easily digested carbohydrate. It is attractive, due to its unique properties, such as hypo allergenicity, colour lessness, bland taste and a high amount of easily digested carbohydrates, making it desirable in celiac patients. Quinoa (Chenopodium quinoa Wild) is pseudo cereal belongs to Chenopodiaceae family. It is richin high biological-value proteins, fibre, essential fatty acid, vitamins, and minerals. It has low glycaemic index and rich in various phytochemical compounds.

Therefore, it could be used as a functional compound in gluten-free bread with good rheological and sensory characteristic due to its desirable chemical composition and good nutritional value (Repo-Carrasco et al., 2003). Thus, Quinoa and rice flour is one of the most emerging healthy alternatives to gluten containing grains in the gluten-free diet as it is a good source of proteins and a wide range of nutrients. They have shown positive effects on the rheological and sensory characteristics of bakery products, such bread and cookies with good nutritional quality. The aim of the present work is to formulate the gluten free bread by using rice flour, and quinoa flour. Then physicochemical, nutritional properties and consumer acceptability of formulated products were studied.

\section{Materials and Methods}

\section{Development of products}

The basic recipe of formulation for the breads was performed according to Aastha Deswal et al., 2015. The treatment includes Rice flour (30-70\%) and Quinoa flour (20-40\%) that it is clearly present in table 1 . Baking was done in an oven at baking temperature between 170 ${ }^{0} \mathrm{C}-190^{\circ} \mathrm{C}$ and baking time $30-40 \mathrm{~min}$. After baking the loaves were cooled at room temperature, sliced and packed in polyethylene bags.

\section{Physicochemical properties of flour}

\section{Water absorption capacity}

Water absorption capacity was determined by following the procedure of Saetung (2010) with little modification. One gram of each 
flour sample was mixed to $10 \mathrm{ml}$ of distilled water. Then, slurry was vortexes for one min and allowed to stand for $30 \mathrm{~min}$ and then centrifuged at $3000 \mathrm{rpm}$ for 10 minutes. Excess water was decanted and samples were allowed to drain.

\section{Bulk Density}

It was measured by following the procedure of Saetung (2010). Take 10gms of tested flour in a $25 \mathrm{ml}$ graduated cylinder and pack it by giving a gentle tapping of the cylinder. The final volume of the test flour was measured and expressed as $\mathrm{g} / \mathrm{ml}$.

\section{Foaming capacity}

The foam capacity was determined using the method of Saetung (2010). Take $2 \mathrm{~g}$ of the flour and blend into $100 \mathrm{ml}$ of distilled water for $6 \mathrm{~min}$ at room temperature and then mixtures were immediately placed in a $250 \mathrm{ml}$ measuring cylinder. The volume of the foam was recorded. It was expressed as the \% increases in the volume.

\section{Swelling Capacity}

\section{Procedure}

$10 \mathrm{ml}$ of water taken into measuring cylinder and add $1 \mathrm{~g}$ of sample then mark the bed volume. Incubate for 18 hours, again take bed volume.

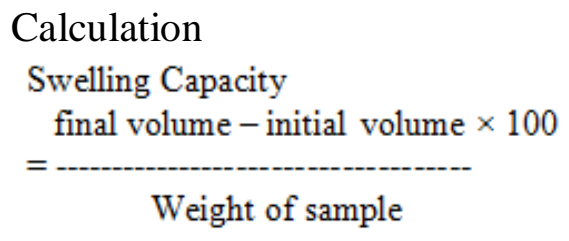

\section{Emulsion capacity}

The emulsion capacity was determined by the method of Martha Padial et al., 2010 with little modification. Emulsion (1 g sample, 10 $\mathrm{ml}$ distilled water, and $10 \mathrm{ml}$ soybean oil) was prepared in calibrated centrifuged tube and the mixture was centrifuged at $2000 \mathrm{~g}$ for $5 \mathrm{~min}$. The ratio of the height of emulsion layer to the total height of the mixture was calculated as emulsion activity in \%. The capacity of the emulsion of the sample was estimated after heating it contains in calibrated centrifuged tube at $80^{\circ} \mathrm{C}$ for $30 \mathrm{~min}$ in a water bath followed by cooling with tap water for $15 \mathrm{~min}$ and then centrifuged at $2000 \mathrm{~g}$ for $15 \mathrm{~min}$. The emulsion capacity (\%) was calculated as the ratio of the height of emulsified layer to the total height of the mixture.

\section{Sensory characteristic of the gluten free bread}

Sensory evaluation of the food products for their acceptability was done by panel members of 10 judges. Panel members are selected based on their performance in initial evaluation trails. Sensory descriptors o the samples were appearance, colour, aroma, taste, texture and overall acceptability. The nine-point hedonic scale score card, purposefully made for analysis was used for sensory evaluation (Sri Lakshmi 2014).

\section{Nutritional analysis of gluten free flour and bread}

The chemical analysis of the flour and developed bread ingredient was done by the standardized procedure of AOAC (2010).

\section{Shelf life of bread}

Shelf-life of optimized $\left(\mathrm{T}_{2}\right)$ gluten free bread includes TPC, Coliform, Yeast and Mould count was done at 1,3,6,9 days. The total plate count $(\mathrm{CFU} / \mathrm{g})$ was determine by the standard plate count method on MRS agar plates and incubating for $48 \mathrm{~h}$ at $37{ }^{\circ} \mathrm{C}$. The yeast and mold count of gluten free bread was determine using potato dextrose agar medium after incubating for $48 \mathrm{~h}$ at $37^{\circ} \mathrm{C}$. The coliform 
bacteria on the MacConkey agar was done after incubated at $37^{\circ} \mathrm{C}$ for $48-72$ hours.

\section{Statistical analysis}

The data was statistically analysed by using Analysis of variance (Two-way ANOVA or Two-way classification) technique. A significant difference between the treatments was determined by using CD (Critical Difference) test (Appendix). ' $t$ ' Test was performed for comparing the difference in the nutritional content between control and best treatment of the developed food products (Chandel, 2006).

\section{Results and Discussion}

\section{Physicochemical Properties of Gluten Free Flour}

The physicochemical properties of gluten free flours were shown in figure 2. The result of our study reported that quinoa flour (15.50\%), exhibit higher water absorption capacity than rice flour $(12.7 \%)$.

Good water absorption capacity is a desirable consistency to formulate sauces, dough, bakery products. High water absorption capacity is due to the presence of more hydrophilic constitutes and it suggest that the flour could be used for bakery products especially breads and cakes.

The value of swelling capacity and emulsion stability of quinoa flouris 19.43 and 47.03 respectively as shown in the below figure 3 . Swelling capacity indicate the ability of grain to absorb water and swell to give desirable volume.

It indicates the extent of associative forces in the starch granules and is considered a quality measure in bakery products. Lower value of swelling capacity (16.76) and emulsion stability (42.84) of rice flour might be attributed on size of particles and species varieties. Although, rice flour has high foaming capacity (18.63), and bulk density $(0.813)$ as shown in table 3.

High foaming stability signify the stability of large air bubbles. This indicate that air bubbles of rice flour particles are not easier to collapse and surrounded by flexible protein film.

The bulk density is the function of mass and volume; it could determine the handling requirement and closeness of packaging as shown in figure 2. In consistent to present study, ogungbenle (2010) found that quinoa has a high-water absorption capacity and low foaming capacity and stability that lead to the good leavened baked product.

\section{Sensory characteristic of gluten free bread}

\section{Colour and appearance}

Figure 1 shows that the mean of sensory scores obtained for gluten free bread in relation to colour and appearance, express that $\mathrm{T}_{2}$ (8.1)has the highest score (8.1), followed by $\mathrm{T}_{1}$ (7.8), $\mathrm{T}_{0}$ (8.1) and $\mathrm{T}_{3}$ (7.75). It indicates that the treatment $\mathrm{T}_{2}(30$ was liked very much by the responders, whereas $T_{o}$ was liked moderately regarding the colour and appearance of gluten free bread by the responders.

\section{Texture}

Figure 1 shows that the mean of sensory scores obtain and analysed for gluten free bread in relation to texture, shows that $T_{2}$ has the highest score (8.1), followed by $\mathrm{T}_{1}(7.8)$, $\mathrm{T}_{\mathrm{o}}$ (8.1) and $\mathrm{T}_{3}$ (7.75). It indicates that the treatment $\mathrm{T}_{2}$ was liked very much by the responders, whereas $T_{0}$ was liked moderately regarding the colour and appearance of gluten free bread by the responders. 


\section{Taste and flavour}

Figure 1 shows that the mean of sensory scores obtain and analysed for gluten free bread in relation to taste and flavour, shows that $\mathrm{T}_{2}$ has the highest score (8.1), followed by $\mathrm{T}_{1}$ (7.8), $\mathrm{T}_{\mathrm{o}}(8.1)$ and $\mathrm{T}_{3}$ (7.75).

It indicates that there is a significant difference between the all three treatments of gluten free bread regarding their texture, so it can be easily concluded that gluten free bread incorporated with 50\% quinoa flour, $40 \%$ rice flour, 5\% xanthan gum, $5 \%$ yeast, $10 \%$ skim milk powder i.e., $T_{2}$ (8.2) has good consistency and is best from other 2 treatments.

\section{Overall acceptability}

Figure 1 shows that the mean of sensory scores obtained for gluten free bread in relation to overall acceptability, indicates that $\mathrm{T}_{2}$ has the highest score (8.2), followed by $\mathrm{T}_{1}$ (7.1), $\mathrm{T}_{0}(8.1)$ and $\mathrm{T}_{3}$ (7.75). It indicates that there is a significant difference between the all three treatments of gluten free bread regarding their consistency, so it can be easily concluded that gluten free bread incorporated with 50\% quinoa flour, $40 \%$ rice flour, $5 \%$ xanthan gum, $3 \%$ sugar, $5 \%$ yeast, $10 \%$ skim milk powder i.e., $\mathrm{T}_{2}(8.2)$ has good in overall acceptability.

\section{Nutritional composition of the developed products}

The control and treatment samples were analysed and calculated for their various nutrient contents including moisture, ash, protein, fat, and energy calories. Figure 4 present the nutritional composition of gluten free bread and shows that highest moisture content was found in $\mathrm{T}_{0}(19.99 \pm 0.22 \mathrm{~g})$ followed by $T_{1}(19.04 \pm 0.36 \mathrm{~g})$ and $\mathrm{T}_{2}(19.36 \pm 0.07 \mathrm{~g}), \quad \mathrm{T}_{3}(19.81 \pm 0.31)$. Lowest moisture content was found in control
$\mathrm{T}_{1}(19.04 \pm 0.36 \mathrm{~g})$. Although, no significant difference were found in moisture content of $\mathrm{T}_{1}$ and $\mathrm{T}_{2}$. It signifies that $\mathrm{T}_{1}$ and $\mathrm{T}_{2}$ have higher shelf life due to lower moisture content followed by $\mathrm{T}_{3}$ and control has lowest shelf life in comparison to all formulated gluten free bread. The might attribute due to the presence of refined wheat flour in control.

The ash content of gluten free bread varies (0.08 to $0.88 \mathrm{~g})$. Ash content of all treatments were found significant different from each other. The ash content of treatment $\mathrm{T}_{1}$ $(0.88 \pm 0.07 \mathrm{~g})$ was found to be highest followed by $\mathrm{T}_{0} \quad(0.08 \pm 0.31 \mathrm{~g}), \quad \mathrm{T}_{2}(0.88 \pm 0.07 \mathrm{~g}), \quad \mathrm{T}_{3}$ $(0.66 \pm 0.31 \mathrm{~g})$ as shown in figure 4 . The higher ash content signifies the higher mineral content in bread.

Highest ash content in $T_{1}$ signifies the highest mineral content in treatment $\mathrm{T}_{1}$, attributed to higher mineral in quinoa than rice. Minimum ash content found in control, this might be low mineral content in refined wheat flour than quinoa and rice flour (Paulina sarbak et al.,).

The highest protein content found $\operatorname{inT}_{3}(13.98 \pm 0.68 \mathrm{~g})$ followed by $\mathrm{T}_{0}$ $(8.8 \pm 0.18 \mathrm{~g}), \quad \mathrm{T}_{1}(9.66 \pm 0.88), \quad$ and $\mathrm{T}_{2}(8.15 \pm 0.22 \mathrm{~g})$ as shown in figure 4. The protein content was found highest in $\mathrm{T}_{3}$, this might be due to higher protein content of Quinoa and lowest protein content found in control attributed to lower protein content wheat. Breads are low in fat and in present study it ranges from $8.8 \mathrm{~g}$ to 8.15 .

The figure 4 illustrate control have lower fat content and $\mathrm{T}_{1}((3.33 \pm 0.28 \mathrm{~g})$ has highest fat content followed by $\mathrm{T}_{0}(0.72 \pm 0.31), \quad \mathrm{T}_{2}$ $(2.14 \pm 0.31 \mathrm{~g})$ and $\mathrm{T}_{3}(1.56 \pm 0.22 \mathrm{~g})$. (Maria Estela et al., 2013) reported the quinoa and rice flour high in PUFA content than refined wheat flour. It signifies that gluten free bread have high fat content, although they are good fat for health. 
Table.1 Different flours and ingredients taken to make gluten free bread

\begin{tabular}{|c|c|}
\hline Ingredient & Amount \\
\hline Rice flour & $30-70 \%$ \\
\hline Quinoa flour & $20-40 \%$ \\
\hline Skim milk powder & $10 \mathrm{~g}$ \\
\hline Oil/butter & $5 \mathrm{~g}$ \\
\hline Yeast & $6 \mathrm{~g}$ \\
\hline Sugar & $5 \mathrm{~g}$ \\
\hline Xanthan gum & $0.5 \mathrm{~g}$ \\
\hline
\end{tabular}

Table.2 Control and treatment combinations of gluten free bread

\begin{tabular}{|c|c|c|c|c|}
\hline Treatments & $\mathbf{T}_{\mathbf{0}}$ & $\mathbf{T}_{\mathbf{1}}$ & $\mathbf{T}_{\mathbf{2}}$ & $\mathbf{T}_{\mathbf{3}}$ \\
\cline { 1 - 4 } Ingredients & & & & - \\
\hline Refined wheat flour(g) & 80 & - & - & - \\
\hline Rice flour(g) & - & 35 & 50 & 60 \\
\hline Quinoa flour(g) & - & 45 & 30 & 20 \\
\hline Xanthan gum(g) & 0 & 0.5 & 0.5 & 0.5 \\
\hline Skim milk powder(g) & 10 & 10 & 10 & 10 \\
\hline Sugar(g) & 5 & 5 & 5 & 5 \\
\hline Oil/ butter(g) & 2 & 1.5 & 1.5 & 1.5 \\
\hline Yeast(g) & 3 & 3 & 3 & 3 \\
\hline Total & 100 & 100 & 100 & 100 \\
\hline
\end{tabular}

Table.3 Shelf life of optimized gluten free bread $\left(\mathrm{T}_{2}\right)$

\begin{tabular}{|c|c|c|c|c|}
\hline (Day 1) & (Day3) & (Day6) & (Day9) \\
\hline $\begin{array}{c}\text { Total plate } \\
\text { count (TPC)- } \\
\text { log CFU/g }\end{array}$ & 2.55 & 3.25 & 5.38 & 7.13 \\
\hline $\begin{array}{c}\text { Yeast / Mould } \\
\text { (CFU/g) }\end{array}$ & $1.1 \times 10^{1}$ & $1.9 \times 10^{1}$ & $2.6 \times 10^{2}$ & $3.1 \times 10^{4}$ \\
\hline Coliform & 0 & 0 & 0 & 0 \\
\hline
\end{tabular}


Fig.1 Average sensory scores of controls and treated samples of bread

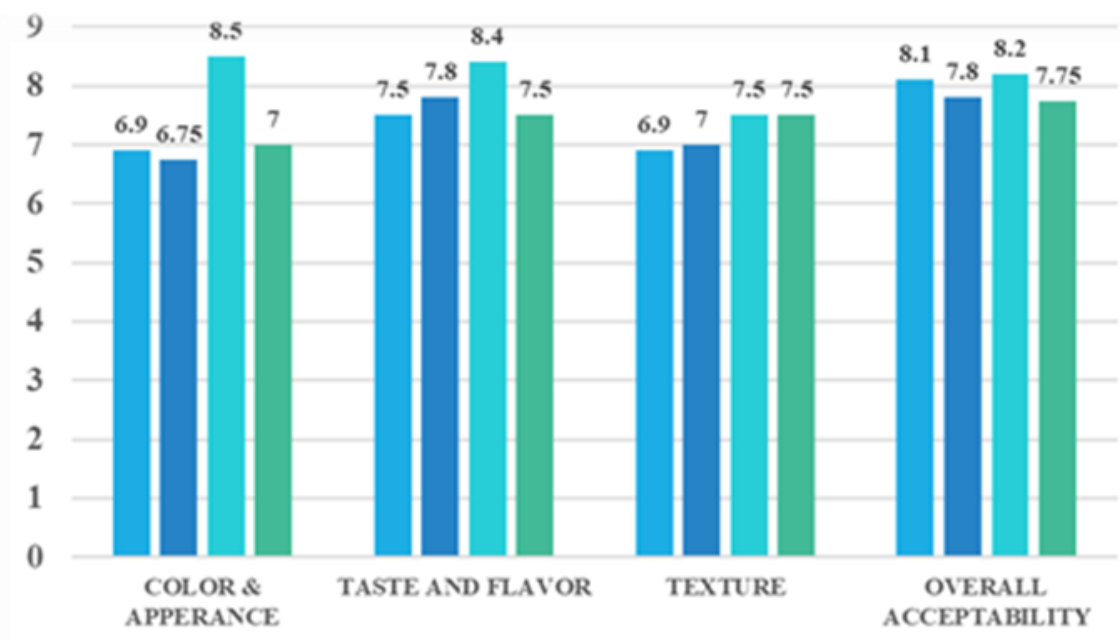

Fig.2 Physicochemical properties of gluten free flour
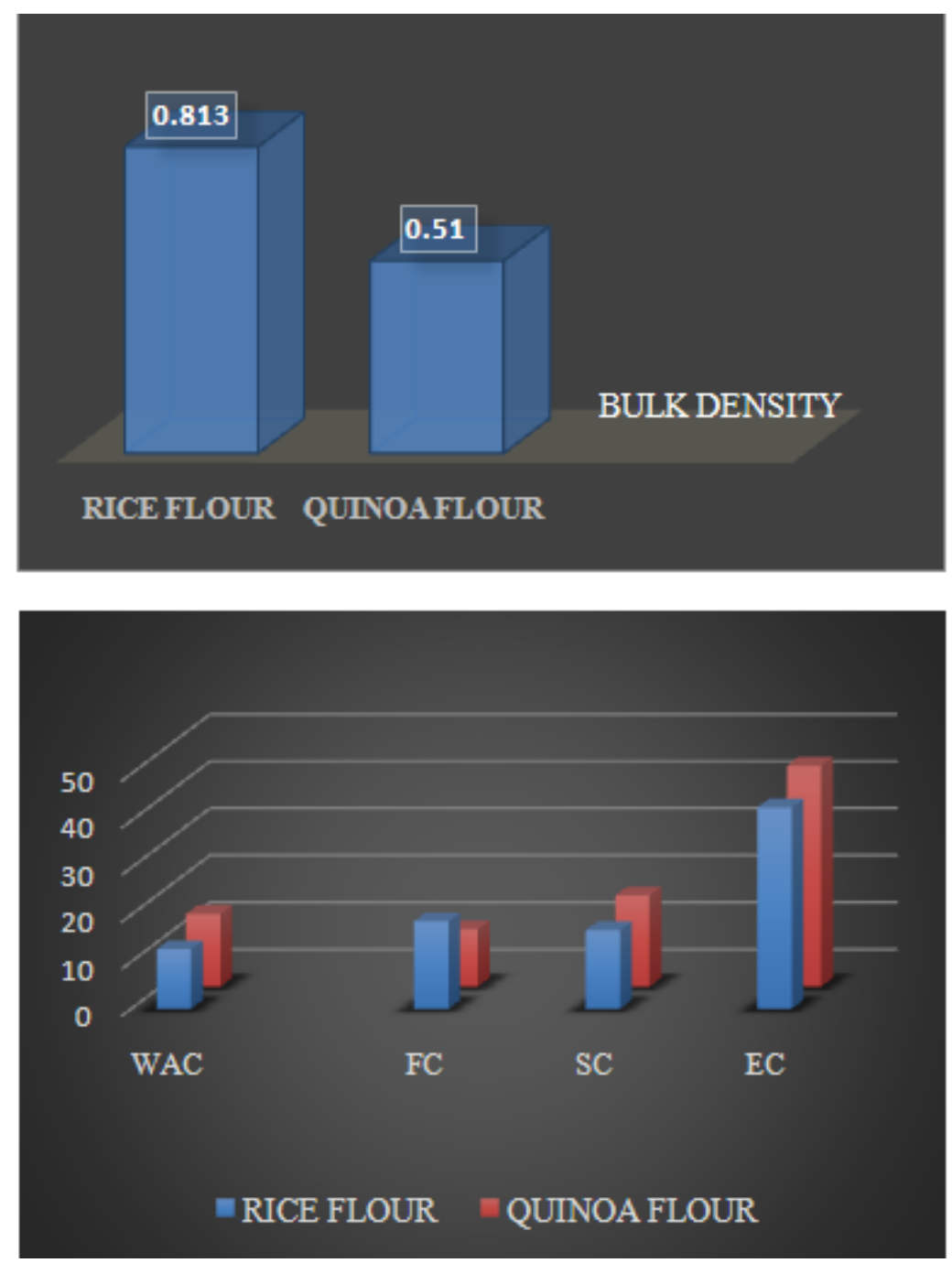
Int.J.Curr.Microbiol.App.Sci (2021) 10(12): 80-90

Fig.3 Physicochemical properties of flour

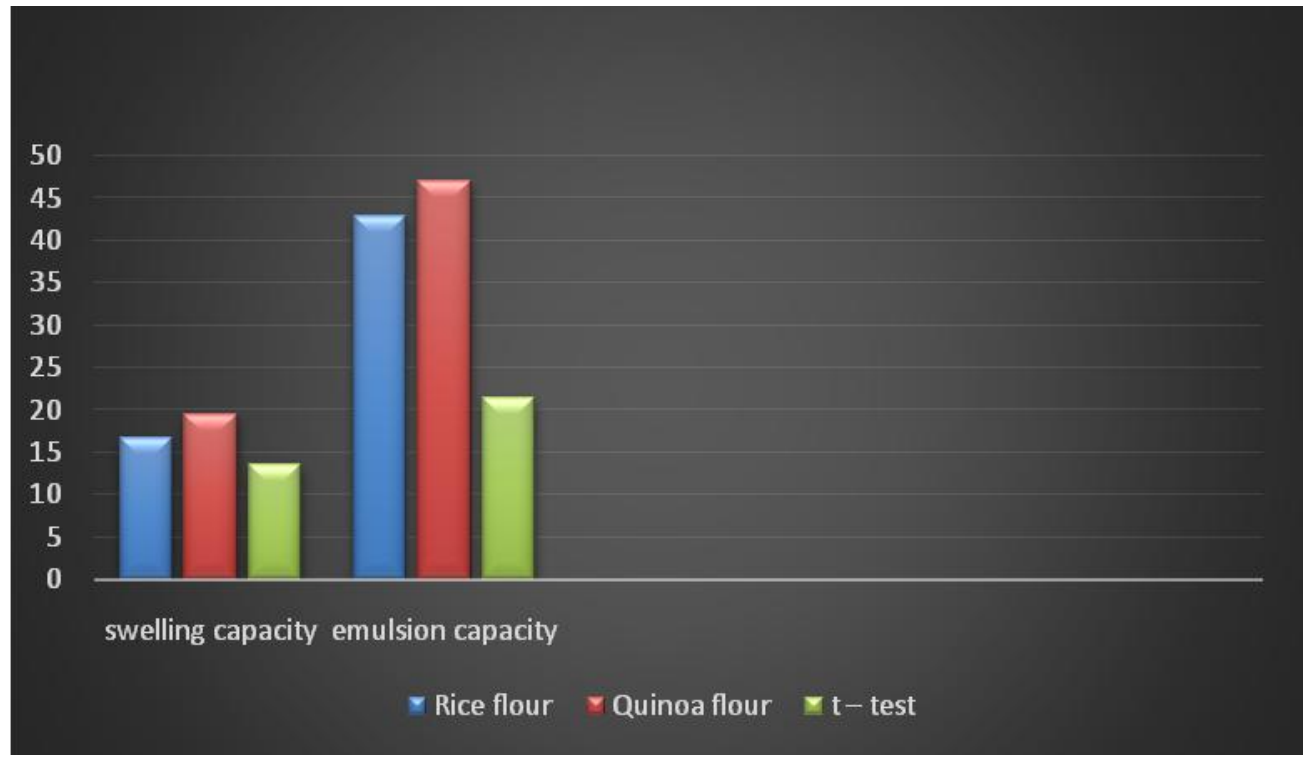

Fig.4 Nutritional composition of gluten free bread

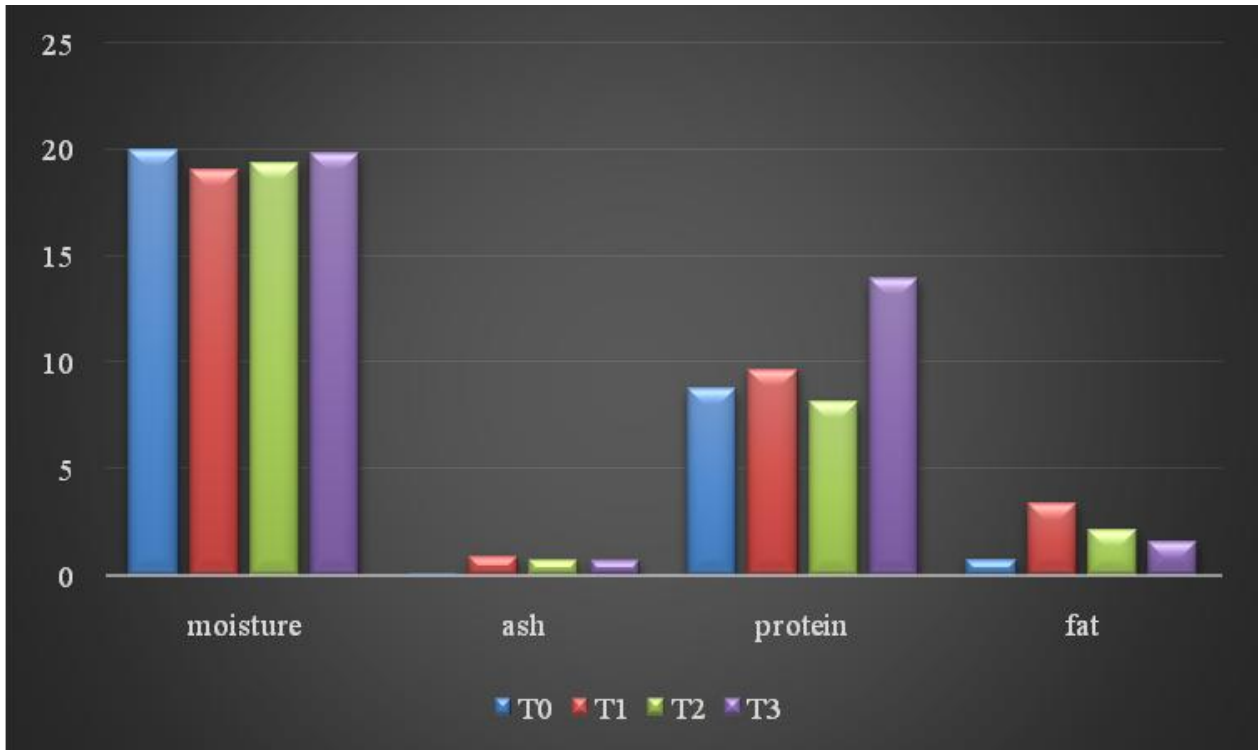


Fig.5 Nutritional composition of gluten free bread

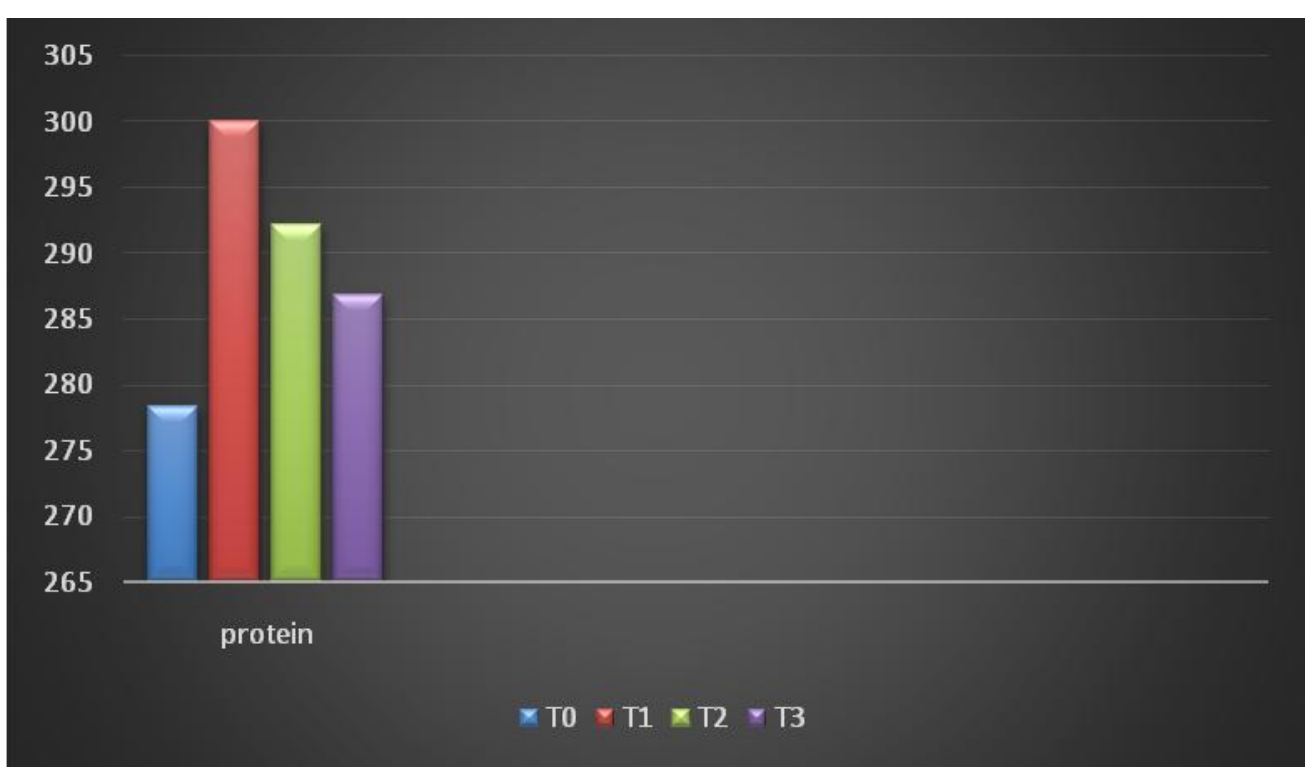

Energy content is high in $\mathrm{T}_{1}(300.1 \pm 0.25 \mathrm{~g})$ followed by $\mathrm{T}_{0}(278 \pm 0.28), \mathrm{T}_{2}(297.2 \pm 0.28 \mathrm{~g})$, and $\mathrm{T}_{3}(286 \pm 0.19 \mathrm{~g})$, respectively as shown in figure 5. Although no significant difference is found in energy content of $\mathrm{T}_{1}$ and $\mathrm{T}_{2}$. The low energy content in control is attributed to low content of macronutrients. It signifies that gluten free bread has the good energy content because the quinoa flour and rice flour are rich in protein and fat. The nutrient contents shows that the incorporation of quinoa flour, rice flour in the product of gluten free bread, was good to enhance the nutritional values of it and also good for preventing celiac diseases.

\section{Shelf life of gluten free bread}

The shelf-life of optimized $\left(\mathrm{T}_{2}\right)$ gluten free bread includes TPC, Coliform, Yeast and Mould count is presented in table 3 . The total plate count on day 1, 3, 6 and 9 of optimized gluten free bread $\left(\mathrm{T}_{2}\right)$ is $2.55 \log$ CFU/g, 3.25 $\log \mathrm{CFU} / \mathrm{g}, 5.38 \log \mathrm{CFU} / \mathrm{g}$ and $7.13 \mathrm{log}$ $\mathrm{CFU} / \mathrm{g}$ respectively. According to AOAC, the TPC for bread should be $>0.88-6.13 \log$ CFU/g. In the present study, we found that on $6^{\text {th }}$ day the TPC is lower than recommended safety level and on $9^{\text {th }}$ day, the plate count is higher than recommended. Therefore, the present study found that the optimized bread is safe up to the $6^{\text {th }}$ day. The mould spoilage accounts for between 1-5\% depending on the season. The total yeast and mould count of the bread ranged from $1.1 \times 10^{1}-8.0 \times 10^{4}$. The yeast and mould count of optimized bread is $1.1 \times 10^{1}$ in day one, $1.9 \times 10^{1}$ in day $3,2.6 \times 10^{2}$ in day 6 , $3.1 \times 10^{4}$ in day 9 . Therefore, the present study found that the optimized bread is safe up to $6^{\text {th }}$ day. The yeast and mould count found within recommended range up to $9^{\text {th }}$ day and coliform count was nil from day 1-9.These results consistent with other reported results of shelflife of gluten free bread.

The finding of present study reveals that Quinoa and Rice flour enhance the nutritive value of gluten free bread. The treatment $\mathrm{T}_{2}$ (50:30) was highly acceptability on the basis of overall acceptability for the gluten free bread. The nutritional composition of all treatments in the developed products was higher in comparison with control. The present study found that the optimized bread is safe up to $6^{\text {th }}$ day. The results of the study arouse the need of further improvement and optimization of gluten free bread. 


\section{Acknowledgement}

Authors would like to express my gratitude to my supervisor, Dr. Neha Mishra, and lab technician. Also, author would like to thank my friends and family who supported me and guided me throughout this project. cannot express enough thanks to my committee for their continued support and encouragement.

\section{References}

Aaron, 2015. Food Industrial Microbial Transglutaminase in Celiac Disease. International Journal 1-6.

Aastha Deswal, Navneet Singh Deora, Hari Niwas Mishra, 2015. Product development in gluten free product; Food science and technology international 21(5), 364-379.

Andreas Houben, Agnes Hochstotter, Thomas Becker, 2012. possibilities to increase the quality in gluten- free bread production., European Food Research and Technology. 235 (2), 195-208.

Anuchita Moongnarm, Tanongsak Moontree, pisanDeedpinrum, Kiratipadtong, 2013. Functional properties of rice flour; Department of food technology and nutrition, faculty of technology, university Mahasarakham, Thailand, 44150.

Arendt, E. K. and F. D. Bello., 2008. Rheology and texture properties of surimi gels. Inc. p 491-582.

Arendt, E. K. and F. D. Bello, 2008. Functional cereal products for those with gluten intolerance. In: Technology of Functional Cereal Products, ed. B. R. Hamaker. Cambridge, England: Wood head Publishing Ltd.

Azwinahmad, Mimi SakinahAbdMunaim and S. MohdAhmadi, 2016.'Optimization of gluten free bread formulation by adding Xanthan Gum, using responses surface methodology", The national conference for postgraduate research. University Malaysia Pahang. 07-18.

Baik O. D., M, Marcotte, S. S. Sablani, and F. Castaigne, 2001. Thermal and physical properties of bakery products," critical reviews in food science and nutrition" journal. 41:321-352.

Bareboft and Joseph, 2004. The Preservation of Food Nutrients, Journal of America and Diet Association. 13 - 259.

Belderok, B., Mesdag, J., \& Donner, D. A, 2000. Bread-making quality of wheat (p.3). Springer. ISBN 0-7923-6383-3.

Capriles V D, Areas J G, 2014. novel approaches in gluten-free bread making: interface between food science, nutrition, and health. Comprehensive review food science. 13(5):871-890.

Chandel, S. R. S, 2006. Analysis of Variance, Handbook of Agriculture Statistics $4^{\text {th }}$ edition $13-17$.

Crockett, R. B. S., 2009. The Physicochemical Properties of Gluten-free Dough with the Addition of Hydrocolloids and Proteins, M.Sc., Ohio State University, Ohio, USA.

Cornejo F, rosell C M, 2015. Physicochemical properties of long rice grain varieties in relation to gluten free bread quality. LWT- food scitechnol. 62(2): 12031210.

Dartois A, Singh J, Kaur L, Singh H, 2010. influence of guar gum on the in vitro starch digestibility; rheological and microstructural characteristics. National agricultural library journal Food biopsies. ISSN: 1557-1858.

Department of Human Nutrition and Hygiene, Poznan University of Life Sciences, Wojskapolskiego. 31, 60-624.

Denisse Bender, Regine Schon Lechner, 2020. Innovative approaches towards improved gluten-free bread properties; Journal of Cereal science. 91-102904. 
Gopalan, C., Ramasastri, B. V. and Balasubramanian, S. C, 2004. Nutritive Value of Indian Foods. National institute of nutrition (NIN). Indian Council of Medical Research, Hyderabad.

Gulsum M. Turkut, Hulya Cakmak, Seher Kumcuoglu, Sebnem Tavman, 2016. Quinoa flour on gluten - free bread batter and bread quality. Journal of cereal science.(69) 175-181.

Hiroyuki Yano, Akiko Fukui, Keiko Kajiwara, Isao Kobayashi, KohichiYoza, AkiyoshiSatake, Masumi Villeneuve, 2017. Development of Gluten free rice bread stabilization as a possible batterswelling mechanism. LWT - Food Science and Technology. 632-639.

Le Thi Kim Loan, Nguyen Minh Thuy, Nguyen Van Thanh, 2017. Optimization of formulation of gluten free rice bread using Response Surface Methodology. International Journal of Science and Research. 2319-7064.

Maria Estela Matos Segura, Cristina M. Rosell, 2013. Gluten free bread compositions. Department of food technology. 26(4) 60-624.

Mohammadi M., N, sadeghnia, M. H. Azizi, T. R. Neyestani, A. M. Mortazavian, 2014, et al., "Development of gluten free bread using hydrocolloids: xanthan and CMC", journal of industrial and engineering chemistry". 20: 1812_1818.

Nitcheu Ngemakwe P H, M Le Roses- Hill, V
A Jideani, 2015. Advances in gluten free bread technology; Food science and technology International. 21 (4), 256,276 .

Ogungbenle. H. N, 2003. Nutritional evaluation and Functional Properties of quinoa flour. Int. J. Food sci. nutr. 54 (2). $153-158$.

Pruska-kedzior. A., kedzior, Z, Goracy. M... pietrowska, K., prybylska, A., Spychalska, K, 2008. Comparison of rheological, fermentive and baking properties of gluten free dough formulations. Eur. Food Res. Technol. 227: 1523-1536.

Repo-Carrasco, R., Espinoza, C., \& Jacobsen, S. (2003). Nutritional value and use of the Andean crops quinoa. Food reviews international. 19,179-189.

Swamy, K. R., Nath, P. and Ahuja, K. G, 2014 Vegetables for Human Nutrition and Health. In: Nath, P., Ed., The Basics of Human Civilization-Food, Agriculture and Humanity, V-II-Food, Prem Nath Agricultural Science Foundation (PNASF), Bangalore \& New India Publishing Agency (NIPA), New Delhi. 145-198.

Troncone, R. \& Jabri, B, 2011 Celiac disease and gluten sensitivity. J. Intern. Med. 269: 582-590.

Vaibhavi, Jakhetia, Rakesh Patel, Pankaj Khatri, Neeraj Pahuja, Sunil Garg, Anu Priya Pandey, Sonu Sharma, 2010. Journal of Advanced Scientific Research. 1(2); $19-23$; $0976-9595$.

\section{How to cite this article:}

Mandaloju Pooja, Mishra Neha and Prasad Ranu. 2021. Formulation and Characterization of Gluten Free Bread based on Quinoa and Rice Flour. Int.J.Curr.Microbiol.App.Sci. 10(12): 8090. doi: https://doi.org/10.20546/ijcmas.2021.1012.010 